\title{
Emphysematous Pyelonephritis in a Black African Woman Managed with Antibiotics Alone
}

\author{
Kossi Akomola Sabi, Béfa Noto Kadou Kaza*, Eyram Yoan Amekoudi, Jacques Vigan, Vicko Manou, \\ Dazé Apollinaire Gnionsahe
}

Department of Nephrology and Hemodialysis, Sylvanus Olympio University Teaching Hospital, Lomé, Togo

Email: kossi.sabi@gmail.com, ‘bfanotokadoukaza@yahoo.fr, eyramyoan@gamil.com, viques2@yahoo.fr

How to cite this paper: Sabi, K.A., Kaza, B.N.K., Amekoudi, E.Y., Vigan, J., Manou, V. and Gnionsahe, D.A. (2016) Emphysematous Pyelonephritis in a Black African Woman Managed with Antibiotics Alone. Open Journal of Nephrology, 6, 151-156. http://dx.doi.org/10.4236/ojneph.2016.64019

Received: October 1, 2016

Accepted: December 16, 2016

Published: December 19, 2016

Copyright $(92016$ by authors and Scientific Research Publishing Inc. This work is licensed under the Creative Commons Attribution International License (CC BY 4.0).

http://creativecommons.org/licenses/by/4.0/

\section{Abstract}

Introduction: Emphysematous pyelonephritis (EPN) is a severe, life-threatening infection of the renal parenchyma. This condition is characterized by the production of intrarenal and perinephric gas. In the world, the EPN is currently limited to case series reported. No cases have been described in black Africa. Aims: Related a first case of EPN diagnosed and treated in the University Hospital Center Sylvanus Olympio of Lomé in Togo. Observation: A 40 years old woman, with antecedent of diabetes presented pyelonephritis emphysematous class 2 . She was treated successfully with antibiotic alone without using percutaneous drainage or nephrectomy. Conclusion: As reported in every case series, it was a young diabetic patient with a clinical features of acute pyelonephritis which CT scan had helped lay the EPN class 2 diagnosed. The germ was Klebsiella pneumoniae. She was treated with adapted antibiotic alone.

\section{Keywords}

Emphysematous Pyelonephritis, Africa, Togo

\section{Introduction}

Emphysematous pyelonephritis (EPN) is acute necrotizing infection of the kidney characterized by formation of gas in the renal parenchyma [1]. It is a rare infection occurring mostly in patients with diabetes mellitus (DM) or ureteral obstruction [1] [2]; this condition is serious, rapidly life-threatening [3]. The diagnosis is confirmed by computed tomography (CT), the gold standard for diagnosis and radiological classification that has therapeutic and prognostic value [3] [4]. Treatment options for EPN have evolved over the years, from invasive surgery to more conservative approaches including percutaneous catheter drainage (PCD) or the use of a double-J catheter (DBJ). Over 
the last two decades, the implementation of PCD techniques facilitates maximum nephron sparing and restoration of renal function. Percutaneous drainage, rather, is now the gold standard of care and definitive management for the majority of patients with EPN [1] [5]. In the world, after the publication of the first case of EPN by Kelly et al. in 1898 [6], EPN is currently limited to case series reported [5] [7] [8] [9]. In Africa, EPN is summarized by a few sporadic cases reported in North Africa [10] [11]. No cases have been described in black Africa. We related a case of EPN diagnosed and treated in the University Hospital Center Sylvanus Olympio (CHU-SO) of Lomé in Togo and that evolved favorably under antibiotic therapy alone.

\section{Observation}

40 years old woman, with hypertensive and diabetes poorly followed, was admitted to the nephrology department for abdominal pain predominant in the right upper quadrant and pelvis, fever, shivering, headache. Clinical examination noted: hyperthermia $38.2^{\circ} \mathrm{C}$, high blood pressure $140 / 100 \mathrm{~mm} \mathrm{Hg}$, lumbar painful shock right, tachycardia 120 beats per minute, a normal state of consciousness. The diagnostic hypothesis of acute pyelonephritis was raised and a complementary assessment conducted shows acute pyelonephritis due to Klebsiella pneumoniae extended spectrum beta-lactamase (ESBL) with moderate renal impairment (Table 1). Renal ultrasound was objectified a big right kidney abscess with a beach and reverberations aeric under nephritis Emphysematous abscess. An abdominal CT scan shows a large right kidney gaseous density image (Figure 1) confirming the diagnosis of emphysematous pyelonephritis right to Klebsiella pneumoniae class 2 according to classification by Huang and Tseng (Table 2) [8]. A brief short resuscitation with the transfusion of blood and saline rehydration was instituted in emergency followed by empirical antibiotic treatment included ceftriaxone 02 grams per day and metronidazole 500 milligrams (mg) per day after bacteriological samples. Antibiotic treatment was adjusted by imipenem $1000 \mathrm{mg}$ per day in two divided doses for 10 days after confirmation of Klebsiella pneumoniae EPN. An appropriate insulin therapy helped maintain good glycemic control and antihypertensive

Table 1. Evolution of biological parameters.

\begin{tabular}{cccc}
\hline & Parameters & & \\
\hline & Initial & After 4 weeks & After 6 weeks \\
\hline Urea $(\mathrm{g} / \mathrm{l})$ & 0.46 & 0.4 & 0.36 \\
Glycemia $(\mathrm{g} / \mathrm{l})$ & 5 & 1.00 & 1.01 \\
Creatininemia $(\mathrm{mg} / \mathrm{l})$ & 18 & 11 & 9 \\
CRP $(\mathrm{mg} / \mathrm{l})$ & 33.3 & 5.6 & 4 \\
Leukocytes $\left(/ \mathrm{mm}^{3}\right)$ & 11000 & 6000 & 7000 \\
Neutrophil $\left(/ \mathrm{mm}^{3}\right)$ & 9500 & 5600 & 5100 \\
Hemoglobin rate $(\mathrm{g} / \mathrm{dl})$ & 6.7 & 12 & 12 \\
\hline
\end{tabular}

CRP: C Reactive Protein. 


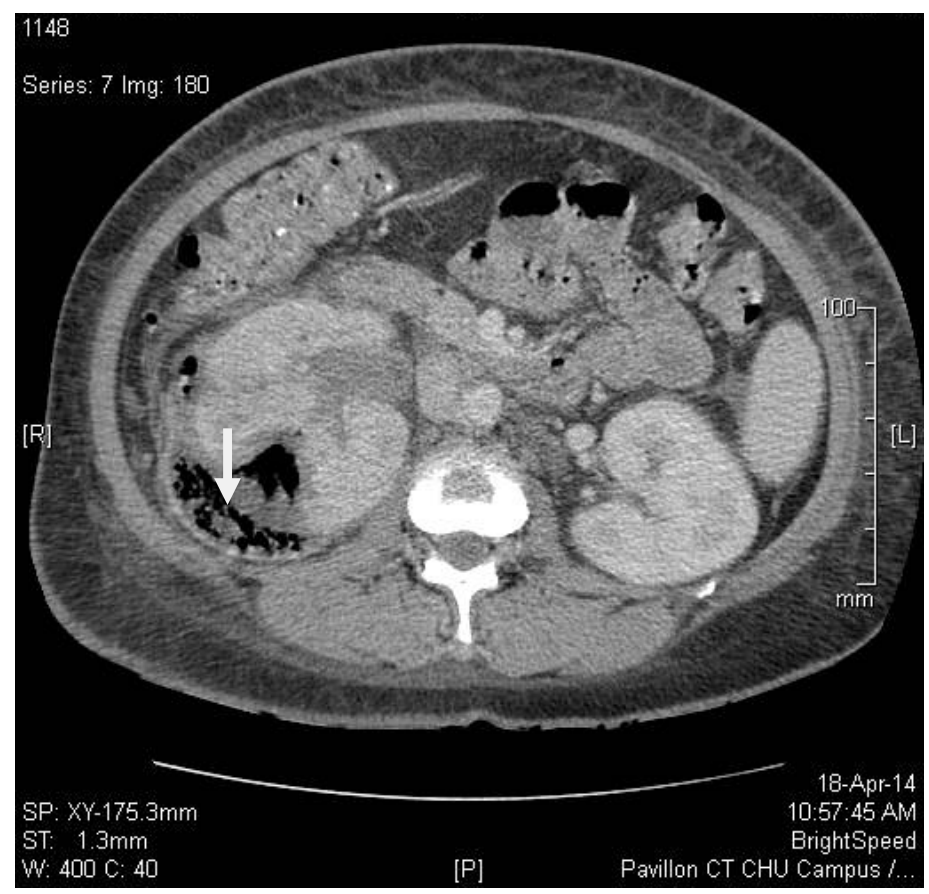

Figure 1. CT scan revealed the presence of gas in the right kidney (class 2) indicated by an arrow.

Table 2. Emphysematous pyelonephritis (EPN) classification by Huang and Tseng [8].

\begin{tabular}{cc}
\hline Class & Description \\
\hline Class I & Gas in collecting system only \\
Class II & Parenchymal gas only \\
Class III a & Extension of gas into perinephric space \\
Class III b & Extension of gas into pararenal space \\
Class IV & EPN in solitary kidney, or bilateral disease \\
\hline
\end{tabular}

treatment with had allowed normalize blood pressure. The clinical outcome was favorable. Patient had left service on the 31st day of hospitalization on insulin and blood pressure medications. Biological and morphological evolution was favorable marked by a return to normal biological parameters (Table 1 ).

\section{Discussion}

Emphysematous pyelonephritis is a severe and necrotizing form of acute bacterial pyelonephritis, caused by gas production in the renal parenchyma. Its prevalence is increasing due to a better understanding of disease, spread of CT scans, or increasing of diabetes incidence [3]. In retrospective study of Ahlering conducted over 5 years, prevalence of EPN was 1.6/1000 admissions [12]. Poorly controlled diabetes is present in $70 \%-80 \%$. It occurs in women in $76.2 \%$ of cases, average age was 55 years [8] [12]. Patient of our observation is female, aged 40 years and diabetic. Gas formation is ex- 
plained by intrarenal process of fermentation of glucose by bacterial infection [13]. In black Africa and in Togo no cases have been reported in the literature. Our case is the first case diagnosed in our clinic. Clinical symptoms are not specific, the usual features is an infectious syndrome with urinary symptoms in a diabetic [5] [12]. The most specific sign but rare is the perception of a subcutaneous crepitus facing kidney signifying the presence of gas, it is only present in $14 \%$ of cases. The causative organism is usually Escherichia coli (60\% of cases) but Klebsiella pneumoniae was found in $25 \%$ of cases , sometimes Pseudomonas or Proteus mirabilis and vulgaris were found [5] [8]. The germ found in our case is Klebsiella pneumoniae ESBL. Ultrasound is interest in the diagnosis of urinary tract obstruction. Abdominal CT certify the diagnosis and clarifies the extent of damage that can sometimes be bilateral. It also helps to the therapeutic decision concerning conservative treatment or radical [5] [8]. In our case the CT scan lesions corresponded to class 2. EPN is a therapeutic emergency. Symptomatic treatment of hemodynamic disorders, hydroelectrolytic strict normalization of blood glucose insulin therapy, and organ dysfunction are essential and must be done in intensive care [13]. The emergency nephrectomy was once considered a treatment of choice for emphysematous pyelonephritis. However, in the absence of poor prognostic factors [1], some authors recommend conservative treatment including medical treatment with percutaneous catheter drainage (PCD) [1] [5]. Appropriate antibiotics based on bactericidal and synergistic combination against Gram negative bacteria and anaerobic must be initiated quickly. This antibiotic can be associated initially with percutaneous drainage. If this fails, nephrectomy must be performed. Antibiotic treatment alone seems suitable for early class disease (class1 and 2) and in inoperable patients or refusing surgery. The patient of our observation has received only medical treatment without percutaneous drainage. The reason for successful of conservative management nowadays is probably because EPN gets picked up early on CT showing very small air pockets. Medical treatment alone is disappointing, overall mortality currently remaining $7 \%-22 \%$ [3] [8]. In our case, the short consultation period (03 days), rapid diagnosis and treatment explain favorably evolution.

\section{Conclusion}

This is first reported case in Black Africa. It was a diabetic young patient with clinical features of acute pyelonephritis which CT had helped to diagnose EPN class 2. The responsible germ was Klebsiella pneumoniae ESBL. Adapted antibiotic therapy allowed achieving cure, without nephrectomy or percutaneous drainage. The EPN can cure with antibiotics alone even at the class 3 [14].

\section{Consent}

Oral consent was obtained from the patient for this publication.

\section{Competing Interests}

All authors disclose no possible conflicts of interest. 


\section{Authors' Contributions}

All authors has made substantial contributions to conception and design, wrote the paper, checked bibliographic reference, read and approved the final manuscript.

\section{References}

[1] Divish, S., Lalit, A., Sanjeev, K.T. and Shaji, T. (2013) Emphysematous Pyelonephritis-A Rare Surgical Emergency Presenting to the Physician: A Case Report and Literature. Indian Journal of Surgery, 75, S272-S274. http://dx.doi.org/10.1007/s12262-012-0690-6

[2] Tseng, C.C., Wu, J.J., Wang, M.C., et al. (2005) Host and Bacterial Virulence Factors Predisposing to Emphysematous Pyelonephritis. AJKD, 46, 432-439.

http://dx.doi.org/10.1053/j.ajkd.2005.05.019

[3] Shioeir, A.A., El Azab, S.M. and El Diasty, T. (1997) Emphysematous Pyelonephritis: A 15 Years Experience with 20 Cases. Urology, 49, 343-346.

http://dx.doi.org/10.1016/S0090-4295(96)00501-8

[4] Michaeli, J., Mdgl, P., Perlberg, S., Heine, S. and Caine, M. (1984) Emphysematous Pyelonephritis. The Journal of Urology, 131, 2113-2118.

[5] Lu, Y.C., Hong, J.H., Chiang, B.J., Pong, Y.H., Hsueh, P.R., Huang, C.Y. and Pu, Y.S. (2016) Recommended Initial Antimicrobial Therapy for Emphysematous Pyelonephritis: 51 Cases and 14-Year-Experience of a Tertiary Referral Center. Medicine (Baltimore), 95, e3573. http://dx.doi.org/10.1097/MD.0000000000003573

[6] Kelly, H. and MacCallum, W. (1898) Pneumaturia. JAMA, 31, 3753-81. http://dx.doi.org/10.1001/jama.1898.92450080001001

[7] Pontin, A.R. and Barnes, R.D. (2009) Current Management of Emphysematous Pyelonephritis. Nature Reviews Urology, 6, 272-279. http://dx.doi.org/10.1038/nrurol.2009.51

[8] Huang, J.J. and Tseng, C.C. (2000) Emphysematous Pyelonephritis: Clinicoradiological Classification, Management, Prognosis, and Pathogenesis. Archives of Internal Medicine, 160, 797-805. http://dx.doi.org/10.1001/archinte.160.6.797

[9] Angulo, J.C., Dehaini, A., Escribaano, J. and Sanchez, M. (1997) Successful Conservative Management of Emphysematous Pyelonephritis Bilateral or in a Solitary Kidney. Scandinavian Journal of Urology and Nephrology, 31, 193-197. http://dx.doi.org/10.3109/00365599709070329

[10] Bensalah, J., Chadli, A., Abnousoufyane, N., Ababou, M.R. and Ousehal, A. (2000) Emphysematous Pyelonephritis in Diabetics. Maghreb Medical, 20, 352-358.

[11] Derouiche, A., Ouni, A., Agreni, A., Slama, A., Ben Slama, M.R. and Chebil, M. (2008) The Management of Emphysematous Pyelonephritis: About 21 Cases. The Journal of Urology, 39, 49-56.

[12] Ahlering, T.E., Boyd, S.D., Hamilton, C.L., Bragin, S.D., Chanrasoma, P.T., Lieskoovsky, G. and Skinner, D.G. (1985) Emphysematous Pyelonephritis: A 5-Year Experience with 13 Patients. The Journal of Urology, 13, 1086-1088.

[13] Kaiser, E. and Fournier, R. (2005) Emphysematous Pyelonephritis: Diagnosis and Treatment. Annals of Urology, 39, 49-60.

[14] Chauhan, V. and Sharma, R. (2015) Emphysematous Pyelonephritis (Class IIIa) Managed with Antibiotics Alone. Hong Kong Medical Journal, 21, 363-365.

http://dx.doi.org/10.12809/hkmj144301 


\section{Abbreviations}

DM: Diabetes mellitus

CT: Computed tomography

Submit or recommend next manuscript to SCIRP and we will provide best service for you:

Accepting pre-submission inquiries through Email, Facebook, LinkedIn, Twitter, etc.

A wide selection of journals (inclusive of 9 subjects, more than 200 journals)

Providing 24-hour high-quality service

User-friendly online submission system

Fair and swift peer-review system

Efficient typesetting and proofreading procedure

Display of the result of downloads and visits, as well as the number of cited articles

Maximum dissemination of your research work

Submit your manuscript at: http://papersubmission.scirp.org/

Or contact ojneph@scirp.org 